\title{
Influence of Al203 Content on Mechanical Properties of Silica-based Ceramic Cores Prepared by Stereolithography
}

\section{Wen Zheng}

Huazhong University of Science and Technology

Jia-Min Wu ( $\nabla$ jiaminwu@hust.edu.cn )

Huazhong University of Science and Technology

Shuang Chen

Huazhong University of Science and Technology

Chang-shun Wang

Huazhong University of Science and Technology

Chun-Lei Liu

Huazhong University of Science and Technology

Shuai-Bin Hua

Huazhong University of Science and Technology

Kang-Bo Yu

Huazhong University of Science and Technology

Jie Zhang

Huazhong University of Science and Technology

Jing-Xian Zhang

Shanghai Institute of Ceramics Chinese Academy of Sciences

\section{Yu-Sheng Shi}

Huazhong University of Science and Technology

\section{Research Article}

Keywords: Silica, Ceramic core, Stereolithography, Al203, Mechanical properties, Hollow blades

Posted Date: May 5th, 2021

DOI: https://doi.org/10.21203/rs.3.rs-479433/v1

License: (c) (1) This work is licensed under a Creative Commons Attribution 4.0 International License.

Read Full License 
Version of Record: A version of this preprint was published at Journal of Advanced Ceramics on September 28th, 2021. See the published version at https://doi.org/10.1007/s40145-021-0513-y. 


\title{
Influence of $\mathrm{Al}_{2} \mathrm{O}_{3}$ content on mechanical properties of silica-based ceramic cores prepared by stereolithography
}

\author{
Wen Zheng ${ }^{a, b}$, Jia-Min Wu ${ }^{a, b^{*}}$, Shuang Chen ${ }^{a, b}$, Chang-Shun Wang ${ }^{a, b}$, Chun-Lei \\ Liu $^{a, b}$, Shuai-Bin Hua ${ }^{a, b}$, Kang-Bo Yu ${ }^{a, b}$, Jie Zhang ${ }^{a, b}$, Jing-Xian Zhang ${ }^{c}$, \\ Yu-Sheng Shi ${ }^{a, b *}$
}

${ }^{a}$ State Key Laboratory of Materials Processing and Die \& Mould Technology, School of Materials Science and Engineering, Huazhong University of Science and Technology, Wuhan, 430074, China

${ }^{b}$ Engineering Research Center of Ceramic Materials for Additive Manufacturing, Ministry of Education, Wuhan 430074, China

c State Key Laboratory of High Performance Ceramics and Superfine Microstructure, Shanghai Institute of Ceramics, Chinese Academy of Sciences, Shanghai, 200050, China

\begin{abstract}
Silica ceramic cores have played an important role in the manufacture of hollow blades due to its excellent chemical stability and moderate high-temperature mechanical properties. In this study, silica-based ceramics were prepared by stereolithography and the influence of $\mathrm{Al}_{2} \mathrm{O}_{3}$ content on mechanical properties of the silica-based ceramics was investigated. With the increase of $\mathrm{Al}_{2} \mathrm{O}_{3}$ content, the linear shrinkage of the silica-based ceramics first decreased and then increased, while the room-temperature flexural strength and the high-temperature flexural strength first increased and then decreased. $\mathrm{As}$ the $\mathrm{Al}_{2} \mathrm{O}_{3}$ content increased to 1.0 vol.\%, the linear shrinkage was reduced to $1.64 \%$ because of the blocked viscous flow. Meanwhile, the room-temperature flexural strength and the high-temperature flexural strength were respectively improved to $20.38 \mathrm{MPa}$ and $21.43 \mathrm{MPa}$ with 1.0 vol. $\% \mathrm{Al}_{2} \mathrm{O}_{3}$ due to the increased $\alpha$-cristobalite and $\beta$-cristobalite content. Therefore, using the optimal content of $\mathrm{Al}_{2} \mathrm{O}_{3}$ in silica-based ceramics can provide excellent mechanical properties and ensure the reliability of silica-based ceramic cores for manufacturing hollow blades.
\end{abstract}

Keywords: Silica, Ceramic core, Stereolithography, $\mathrm{Al}_{2} \mathrm{O}_{3}$, Mechanical properties, Hollow blades

\section{Introduction}

\footnotetext{
${ }^{*}$ Corresponding authors.

1. Tel: +862787558155 ; Fax: +862787558155

E-mail address: jiaminwu@hust.edu.cn (J.-M. Wu).

2. Tel: +862787557042 ; Fax: +862787557042

E-mail address: shiyusheng@hust.edu.cn (Y.-S. Shi)
} 
Silica-based ceramic cores with excellent thermal stability and good core leach have been widely used to fabricate the cavities of turbine engine and gas turbine hollow blades that require high precision and complex shapes [1-5]. However, the traditional preparation method based on investment casting has great limitations in the fabrication process. It not only requires a long production cycle, but also consumes expensive manufacturing costs, which will limit the application and development of silica ceramic cores [6-8]. In order to deal with these problems relevant to the forming of complicated ceramic parts, a new advanced manufacturing technology3D printing technology has been developed [9-12]. Compared with other ceramic 3D printing technologies, stereolithography possesses higher forming precision and better surface quality. The technology can use laser beam to cure ceramic slurry layer by layer and obtain ceramic parts with complex structure by debinding and sintering process [13-17].

The forming process, sintering process and raw materials have great influence on the microstructure and mechanical properties of 3D-printed silica ceramics, whereas cracks often appear in the sintering stage because of shrinkage and phase transformation. Li et al. [18] investigated the effects of sintering temperatures on the mechanical properties of 3D-printed silica ceramic cores based on stereolithography. The room-temperature flexural strengths of silica ceramic cores reached a maximum value of $12.1 \mathrm{MPa}$ at the sintering temperature of $1300^{\circ} \mathrm{C}$. Kotz et al. [19] realized the significance of raw materials for preparing high-quality fused silica glass. They could create arbitrary macro- and microstructures from photocurable silica nanocomposites, thereby broadening the selection of 3D printing materials. Cai et al. [20] pointed out the influence of solid loading and mixing methods on silica glass fabricated by DLP. Their experimental data showed that the viscosity of slurry could be reduced effectively by the multi-step mixing method compared with the one-step mixing method. Liu et al. [21] noticed the effiency problem of fabricating silica glass by stereolithography, thus developing a stereolithography system using top-down method and obtaining the glassware with similar properties to fused silica.

Although stereolithography provides a practical technical way for the efficient and high-quality manufacturing of silica ceramic parts [22-23], there exist some research difficulties. Firstly, the forming mode of layer-by-layer curing can easily cause larger linear shrinkage [24], which will not only affect the mechanical properties of ceramic parts, but also limit the wide 
application of ceramic products [25-26]. Secondly, 3D-printed silica ceramics show lower flexural strength. In addition, the high-temperature strength and room-temperature strength of 3D-printed silica ceramics are rarely investigated at the same time, which may have a strong influence on the performance of ceramic cores. At present, the reinforcements in silica ceramics, such as cristobalite [27] or silicon carbide [4], can improve the mechanical properties effectively by promoting the development of cristobalite. Furthermore, $\mathrm{Al}_{2} \mathrm{O}_{3}$ has a fairly high flexural strength of $472 \mathrm{MPa}$ [28] and thus contributes to enhancing the flexural strength of silica ceramics. $\mathrm{Al}_{2} \mathrm{O}_{3}$ can be also very helpful to reduce the shrinkage of silica ceramics by promoting the the crystallization of the fused silica [29]. Therefore, the $\mathrm{Al}_{2} \mathrm{O}_{3}$ is promising to be regarded as a powerful reinforcement in silica ceramic cores.

In this work, silica-based ceramics added to various $\mathrm{Al}_{2} \mathrm{O}_{3}$ contents via stereolithography were fabricated. The influence of $\mathrm{Al}_{2} \mathrm{O}_{3}$ content on the mechanical properties of silica-based ceramics was investigated, and the room-temperature and the high-temperature mechanical properties of the as-obtained silica-based ceramics were both examined.

\section{Materials and methods}

\subsection{Raw Materials}

The slurry used to prepare silica ceramics consisted of spherical $\mathrm{SiO}_{2}$ powder $(99.9 \%$ purity, Hebei Guihuang Metal Material Co., Ltd.) with an average particle size of $2 \mu \mathrm{m}, \mathrm{Al}_{2} \mathrm{O}_{3}$ powder (purity 99.5\%, average particle size $3 \mu \mathrm{m}$, Hebei Kegong Metallurgical Materials Co., Ltd.), photosensitive resin HDDA (Shanghai Guangyi Chemical Co., Ltd.), polymer dispersant 41000 (Lubrizol Advanced Materials S.L., Spain) and photoinitiator TPO (BASF), Germany). All ceramic powders and auxiliaries can be commercially available.

\subsection{Sample preparation}

The solid loading of each ceramic slurry was set to 45 vol.\%. To match with the solid loading, the $\mathrm{Al}_{2} \mathrm{O}_{3}$ contents of the ceramic powders were 0 vol. $\%, 0.5$ vol. $\%, 1.0$ vol. $\%, 1.5$ vol. $\%$ and 2.0 vol.\%. When weighing $\mathrm{Al}_{2} \mathrm{O}_{3}$ in the preparation of the slurry, the corresponding mass was converted according to the density of $4.0 \mathrm{~g} / \mathrm{cm}^{3}$ provided by the powder manufacturer, and then the composite powders were ball-milled in vacuum. The ceramic slurries were obtained by milling the mixture about 30 minutes at room temperature. Table 1 shows the viscosity of the slurries with different contents of $\mathrm{Al}_{2} \mathrm{O}_{3}$ at the same shear rate of $50 \mathrm{~s}^{-1}$. As a result, all the slurries had good 
rheological properties that the viscosity of them was less than $10 \mathrm{~Pa} \cdot \mathrm{s}$, which is suitable for forming by stereolithography [30-31]. After obtaining the slurries, the green bodies were formed by a 3D printer (Wuhan Intelligent Laser Technology Co., Ltd.). And the sizes of the ceramic green bodies used to test flexural strength were $60 \mathrm{~mm} \times 5 \mathrm{~mm} \times 3.6 \mathrm{~mm}(\mathrm{~L} \times \mathrm{W} \times \mathrm{H})$. With the process parameters optimized, the laser power was $25 \%$, the scanning speed was $3000 \mathrm{~mm} / \mathrm{s}$, and the thickness of each layer was $50 \mu \mathrm{m}$.

Table 1 The viscosity of the slurries with different contents of $\mathrm{Al}_{2} \mathrm{O}_{3}$.

\begin{tabular}{cc}
\hline $\mathrm{Al}_{2} \mathrm{O}_{3}$ content/(vol.\%) & Viscosity/(Pa·s) \\
\hline 0 & 7.66 \\
0.5 & 3.22 \\
1.0 & 4.93 \\
1.5 & 3.74 \\
2.0 & 8.65 \\
\hline
\end{tabular}

Aiming at exploring the suitable thermal treatment, a thermogravimetric analyzer (TGA, PerkinElmer Instrument (Shanghai) Co., Ltd.) was used to analyze the powder grinded from green bodies. The thermogravimetric curve shown in Fig. 1(a) was obtained, and the optimal debinding and sintering process could be determined from the curve analysis. As shown in Fig. 1(b), the resin could be completely removed by holding at $600^{\circ} \mathrm{C}$ for $2 \mathrm{~h}$. Sintered at $1200^{\circ} \mathrm{C}$ for about $6 \mathrm{~h}$, silica-based ceramic samples could achieve a higher degree of densification.
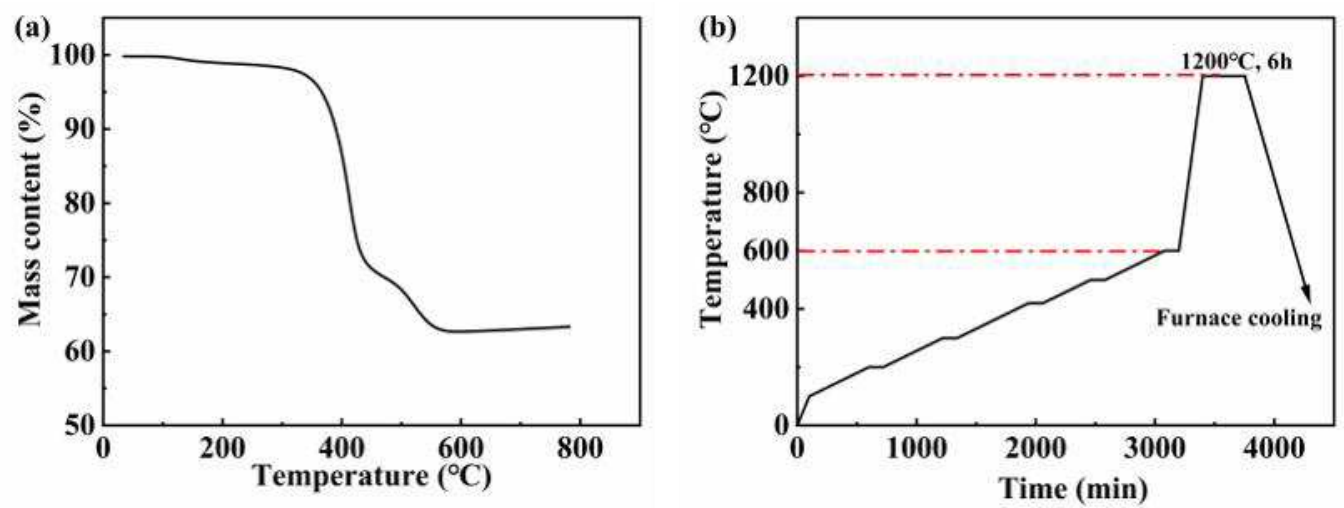

Fig. 1. The thermogravimetric curve and thermal treatment of $\mathrm{SiO}_{2}$ green bodies: (a) TGA curve; (b) The debinding and sintering curve.

\subsection{Characterisation}

To measure the flexural strength of the silica-based ceramic samples at room temperature, an 
electronic universal testing machine (E1000, ITW Group Instron Inc.) was used. The span was adjusted to $30 \mathrm{~mm}$, and the loading rate was set to $0.5 \mathrm{~mm} / \mathrm{min}$. Five samples fabricated with each $\mathrm{Al}_{2} \mathrm{O}_{3}$ content were tested, and the average value was taken as the reference value of the room-temperature flexural strength. Moreover, the high-temperature strength was measured with a heating rate of $5{ }^{\circ} \mathrm{C} / \mathrm{min}$ up to $1550^{\circ} \mathrm{C}$, using a ceramic flexural strength tester (WDW-20, Shenyang Foundry Research Institute Co., ltd). Test methods were performed consistent with the standard HB5352.1-2004. The formula adopted to calculate the flexural strength $(\sigma)$ is as follows:

$$
\sigma=\frac{3 \mathrm{FL}}{2 \mathrm{bh}^{2}}
$$

Where $\mathrm{F}$ is the load when the test sample is broken, $\mathrm{L}$ is the span between the two fulcrums, $\mathrm{b}$ is the width of the test sample, and $\mathrm{h}$ is the thickness of the test sample.

The bulk density and apparent porosity of the silica-based ceramics were measured by Archimedes principle [32]. The Phase transformations of ceramic samples were detected by an X-ray diffractometer (XRD-6100, Shimadzu, Japan). Meanwhile, scanning electron microscopy (SEM) images were observed by field-emission scanning electron microscopy (Quanta650 FEG, FEI, America).

\section{Results and discussion}

The phase compositions of silica-based ceramics with various $\mathrm{Al}_{2} \mathrm{O}_{3}$ contents are gathered in Fig. 2. All sintered ceramics contain quartz resulting from the crystallization of the fused silica. The fused silica has crystallized into quartz at the sintering temperature of $1200^{\circ} \mathrm{C}$ [33]. On the XRD patterns, the peak of $\mathrm{Al}_{2} \mathrm{O}_{3}$ pattern is not very evident due to its low content. Meanwhile, the cristobalite peaks located at about $21.80^{\circ}$ are detected in all ceramic samples that contain $\mathrm{Al}_{2} \mathrm{O}_{3}$ ( 0.5 vol. $\%, 1.0$ vol. $\%, 1.5$ vol. $\%$ and 2.0 vol. $\%$ ), and the intensity increases with the increase of $\mathrm{Al}_{2} \mathrm{O}_{3}$ content, indicating that $\mathrm{Al}_{2} \mathrm{O}_{3}$ can contribute to the formation of cristobalite and its relative content is correlated positively with the $\mathrm{Al}_{2} \mathrm{O}_{3}$ content. The XRD results suggest that the fused silica crystallizes into cristobalite due to the emergence of $\mathrm{Al}_{2} \mathrm{O}_{3}$ that serves as a seed. Therefore, $\mathrm{Al}_{2} \mathrm{O}_{3}$ can promote the development of cristobalite by accelerating the crystallization of the fused silica. 


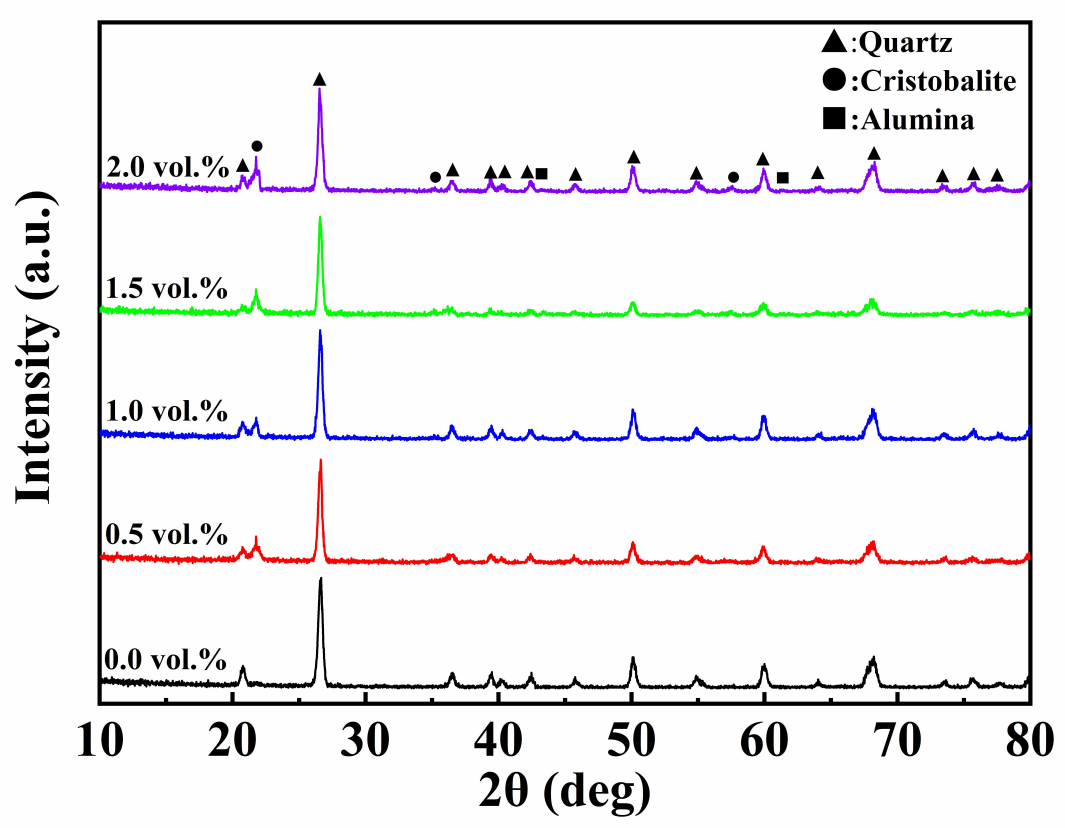

Fig. 2. XRD patterns of silica-based ceramic samples with different contents of $\mathrm{Al}_{2} \mathrm{O}_{3}$.

The microstructures of silica-based ceramics prepared with various contents of $\mathrm{Al}_{2} \mathrm{O}_{3}$ are shown in Fig. 3. Large grains and pores appear in sintered ceramics regardless of the $\mathrm{Al}_{2} \mathrm{O}_{3}$ content. To explore the elemental composition of the sintered ceramics, the ceramic samples sintered at $1200^{\circ} \mathrm{C}$ are observed by EDS and the data are obtained. As shown in Fig. 3(f), the Al and $\mathrm{Si}$ elements are both found in the ceramic samples containing 1.5 vol. $\% \mathrm{Al}_{2} \mathrm{O}_{3}$. $\mathrm{Meanwhile}$ plenty of $\mathrm{SiO}_{2}$ crystals with three-dimensional network structure can be seen because the crystallization temperature of the fused silica is less than $1200^{\circ} \mathrm{C}$ [34]. In the fracture of the silica ceramic without adding $\mathrm{Al}_{2} \mathrm{O}_{3}$, the grains are tightly bonded. After adding $\mathrm{Al}_{2} \mathrm{O}_{3}$, there are more pores in silica-based ceramics than that without $\mathrm{Al}_{2} \mathrm{O}_{3}$. Thus it can be seen that $\mathrm{Al}_{2} \mathrm{O}_{3}$ has some inhibitory effects on the binding between grains. 

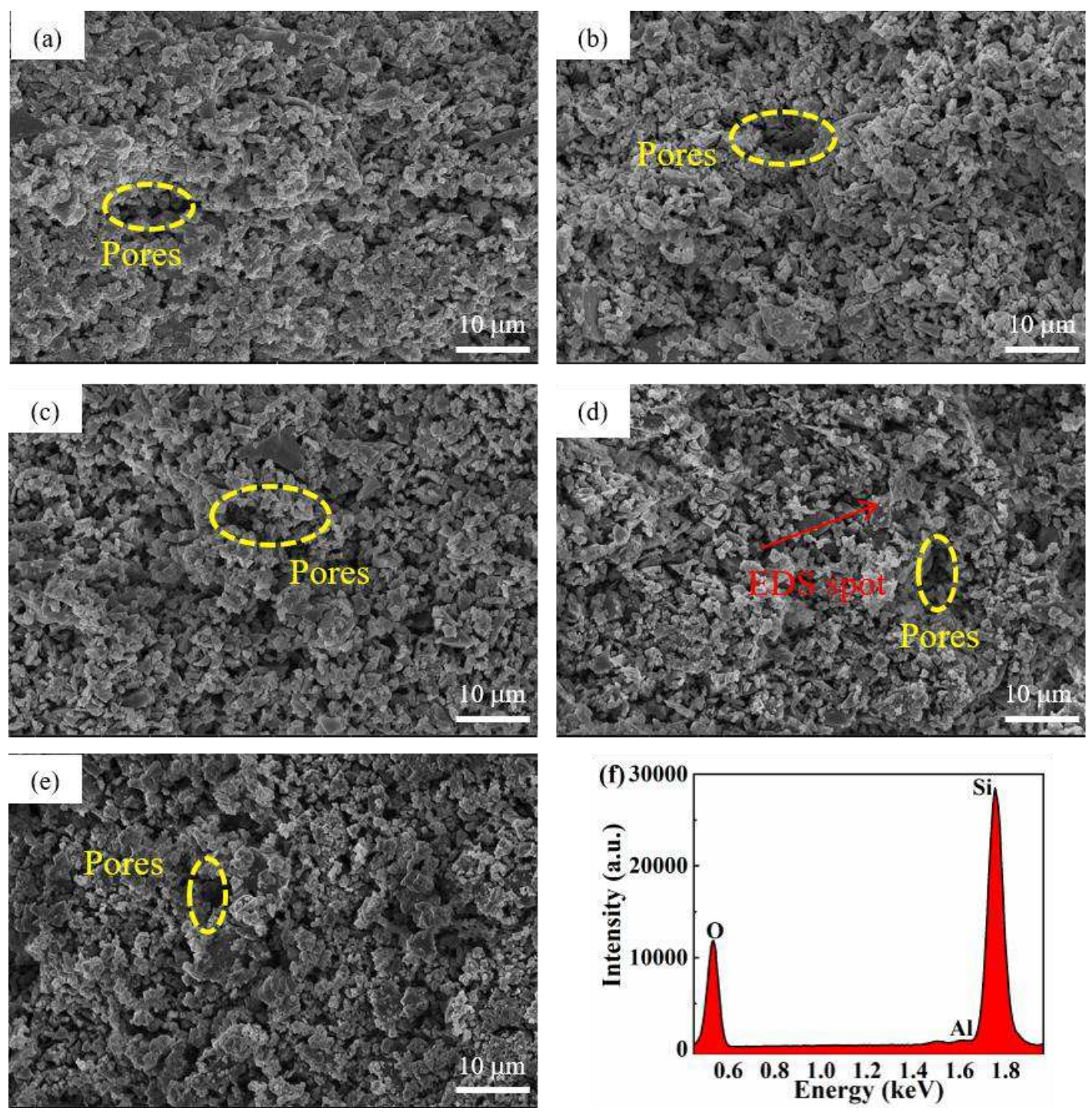

Fig. 3. Microstructures of the silica-based ceramics with various contents of $\mathrm{Al}_{2} \mathrm{O}_{3}$ : (a) 0 vol.\%, (b)

$$
0.5 \text { vol. } \% \text {, (c) } 1.0 \text { vol. } \% \text {, (d) } 1.5 \text { vol. } \% \text {, (e) } 2.0 \text { vol. } \% \text { and }
$$

(f) EDS analysis of the EDS spot with 1.5 vol. $\% \mathrm{Al}_{2} \mathrm{O}_{3}$.

As shown in Fig. 4(a), with the decrease of temperature during the cooling process, $\beta$-cristobalite gradually transforms into $\alpha$-cristobalite in turn, demonstrating the existence of the phase transformation in the silica-based ceramics. Meanwhile, the silica-based ceramics measured at $1550^{\circ} \mathrm{C}$ with 1.0 vol.\% $\mathrm{Al}_{2} \mathrm{O}_{3}$ generate liquid phase, as presented in Fig. 4(b), which is absent under the sintering temperature of $1200^{\circ} \mathrm{C}$, as suggested in Fig. 3. The liquid phase is generated by the melting silica at high temperature, connecting interlayer independent grains [18], as well as increasing the adhesion between ceramic grains and contributing to improved mechanical properties of silica-based ceramics. Furthermore, visible cracks appear in the silica-based ceramics measured at $1550^{\circ} \mathrm{C}$ due to the phase transformation from $\alpha$-cristobalite to stable $\beta$-cristobalite 
during the thermal treatment process.
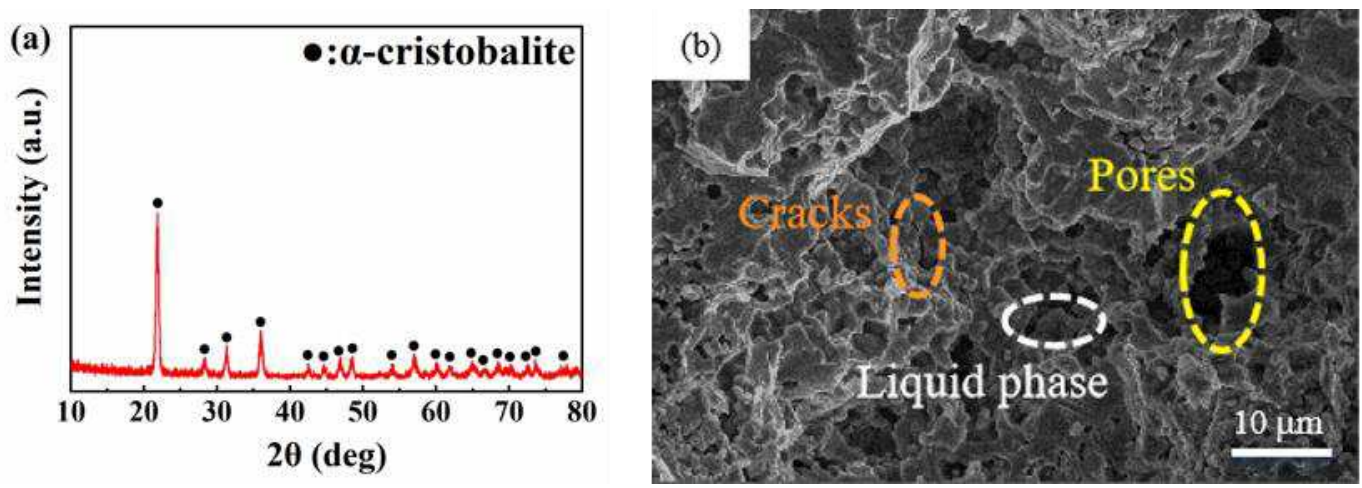

Fig.4 (a) XRD pattern and (b) SEM image of the silica-based ceramics

measured at $1550^{\circ} \mathrm{C}$ with 1.0 vol. $\% \mathrm{Al}_{2} \mathrm{O}_{3}$.

Fig. 5(a) shows the linear shrinkage of silica-based ceramics with different contents of $\mathrm{Al}_{2} \mathrm{O}_{3}$.

The linear shrinkage of the samples is reduced from $2.62 \%$ to $1.64 \%$ as the $\mathrm{Al}_{2} \mathrm{O}_{3}$ increases to 1.0 vol.\%. The crystalline phases in the silica-based ceramics, such as $\mathrm{Al}_{2} \mathrm{O}_{3}$ and cristobalite, can promote the crystallization of the fused silica , but cause relatively small shrinkage. Additionally, the crystalline phases also hinder the viscous flow that is the driving force of the densification of the fused silica, which becomes an obstacle to the shrinkage [35-36]. Consequently, the addition of $\mathrm{Al}_{2} \mathrm{O}_{3}$ degrades the linear shrinkage of the silica-based ceramics. Nevertheless, the linear shrinkage is upgraded to $2.52 \%$ with excessive $\mathrm{Al}_{2} \mathrm{O}_{3}(1.5$ vol.\% and 2.0 vol.\%), which is still lower than the silica ceramics without $\mathrm{Al}_{2} \mathrm{O}_{3}$. When the $\mathrm{Al}_{2} \mathrm{O}_{3}$ content increases to 2.0 vol.\%, the $\mathrm{Al}_{2} \mathrm{O}_{3}$ improves the densification of the ceramics by promoting the growth of coarse grains, as shown in Fig. 3. The improvement has nullified part of the weakening effect caused by the crystalline phases, bringing about the increased linear shrinkage of the silica-based ceramics.

The bulk density and the apparent porosity results of the silica-based ceramics sintered at $1200^{\circ} \mathrm{C}$ are shown in Fig. 5(b). When the $\mathrm{Al}_{2} \mathrm{O}_{3}$ increases from 0 to 1.0 vol.\%, the fused silica is transformed into $\beta$-cristobalite with cubic structure during high-temperature sintering due to the emergence of $\mathrm{Al}_{2} \mathrm{O}_{3}$. Meanwhile, around $250^{\circ} \mathrm{C}$ in the cooling course, the phase transition from $\beta$-cristobalite to $\alpha$-cristobalite with tetragonal structure is realized [37-38]. The phase transition will bring a $5 \%$ reduction of volume, which is likely to cause the propagation of microcracks in silica ceramics [38-39]. Under the combined effect of phase transition and crystallization, the apparent porosity increases and the bulk density decreases. With $\mathrm{Al}_{2} \mathrm{O}_{3}$ added to 2.0 vol.\%, the ceramic grains grow coarsely due to the effect of mass transfer between phases induced by $\mathrm{Al}_{2} \mathrm{O}_{3}$. 
The volume change resulting from coarse grains can improve the densification of silica-based ceramics. At this moment, the improvement of the densification overcomes the weakening effect of phase transition, which leads to the decrease of apparent porosity and the increase of the bulk density.
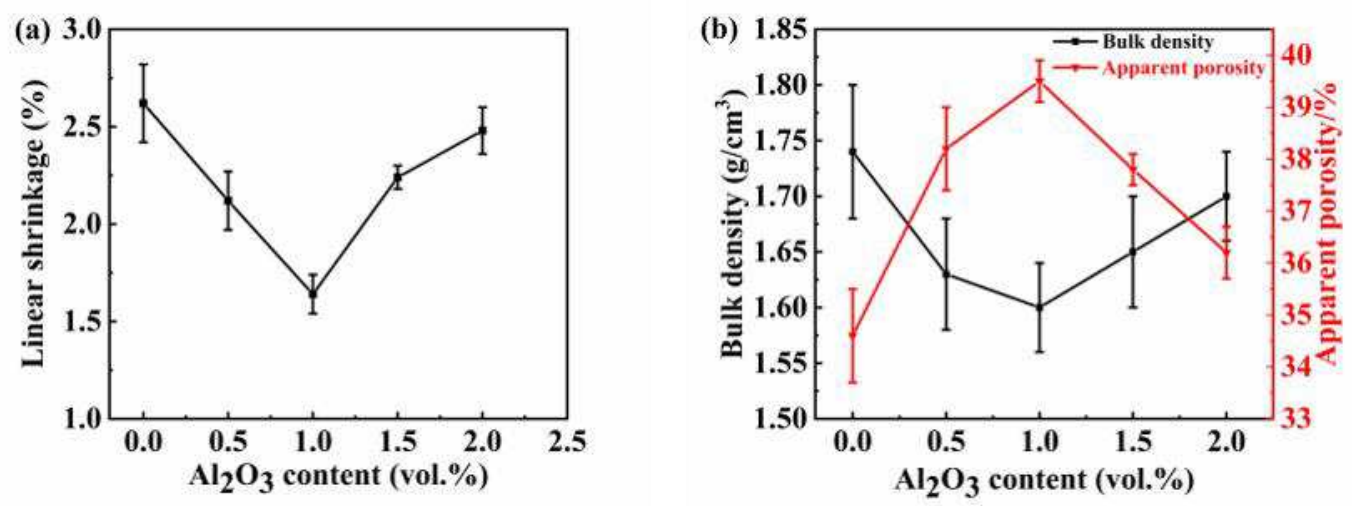

Fig. 5. (a) Linear shrinkage and (b) bulk density, apparent porosity of silica-based ceramics with different contents of $\mathrm{Al}_{2} \mathrm{O}_{3}$.

The flexural strengths of the silica-based ceramics prepared from green bodies with various contents of $\mathrm{Al}_{2} \mathrm{O}_{3}$ printed by the $3 \mathrm{D}$ printer are presented in Fig. 6. It is indicated that the flexural strength of the ceramics all show an opposite tendency to the linear shrinkage. The room-temperature flexural strength of the ceramic samples is improved from $11.56 \mathrm{MPa}$ to 20.38 $\mathrm{MPa}$ as the $\mathrm{Al}_{2} \mathrm{O}_{3}$ increases to 1.0 vol.\%. Compared with the amorphous silica, cristobalite has a higher strength. Therefore, that the fused silica crystallizes into cristobalite can improve the room-temperature flexural strength of the silica ceramics [40-41]. However, the room-temperature flexural strength of the samples decreases when the $\mathrm{Al}_{2} \mathrm{O}_{3}$ increases to 1.5 vol.\% and 2.0 vol.\%. Although cristobalite provides silica-based ceramics with better strength, excessive cristobalite may weaken the trend in turn. The flexural strength of the fused silica ceramics will decrease when the generation of cristobalite is more than $30 \%$ [40]. In this study, it seems easier for the fused silica added $\mathrm{Al}_{2} \mathrm{O}_{3}$ to crystallize into $\alpha$-cristobalite. As a result, the room-temperature flexural strength is enhanced as the $\mathrm{Al}_{2} \mathrm{O}_{3}$ increases to 1.0 vol.\%. But excessive $\mathrm{Al}_{2} \mathrm{O}_{3}(1.5$ vol.\% and 2.0 vol.\%) reduces the internal binding force by accelerating the nucleation of the crystallization process, thereby degrading the flexural strength. Furthermore, both the flexural strength and the apparent porosity of the silica-based ceramics increase as the $\mathrm{Al}_{2} \mathrm{O}_{3}$ increases to 1.0 vol.\%. Although the volume reduction bought by the phase transition is disadvantageous to the 
strength, the enhancement of cristobalite induced by $\mathrm{Al}_{2} \mathrm{O}_{3}$ is much stronger than the weakening effect. Thus, the flexural strength of the silica-based ceramics is also improved with the increase of the apparent porosity.

As for the high-temperature flexural strength, it is improved from 9.39 MPa to $21.43 \mathrm{MPa}$ as the $\mathrm{Al}_{2} \mathrm{O}_{3}$ increases to 1.0 vol.\%, but excessive $\mathrm{Al}_{2} \mathrm{O}_{3}$ (1.5 vol.\% and 2.0 vol.\%) reduces the strength. Obviously, the trend is similar to the flexural strength at room temperature. What's more, there are some different degrees of improvement compared with the room-temperature flexural strength under the same content of $\mathrm{Al}_{2} \mathrm{O}_{3}$. The surface of the fused silica grains will spontaneously separate stable $\beta$-cristobalite crystals out at high temperature [42-43], thus improving the high-temperature strength of silica-based ceramics. However, when the content of $\beta$-cristobalite is too high, the volume effect caused by the secondary crystal transformation of cristobalite produces more microcracks inside the silica ceramics, reducing the high-temperature flexural strength. Arguably, the $\beta$-cristobalite generated under the high temperature of $1550^{\circ} \mathrm{C}$ is highly responsible for improving the high-temperature flexural strength of silica-based ceramics due to its high strength.

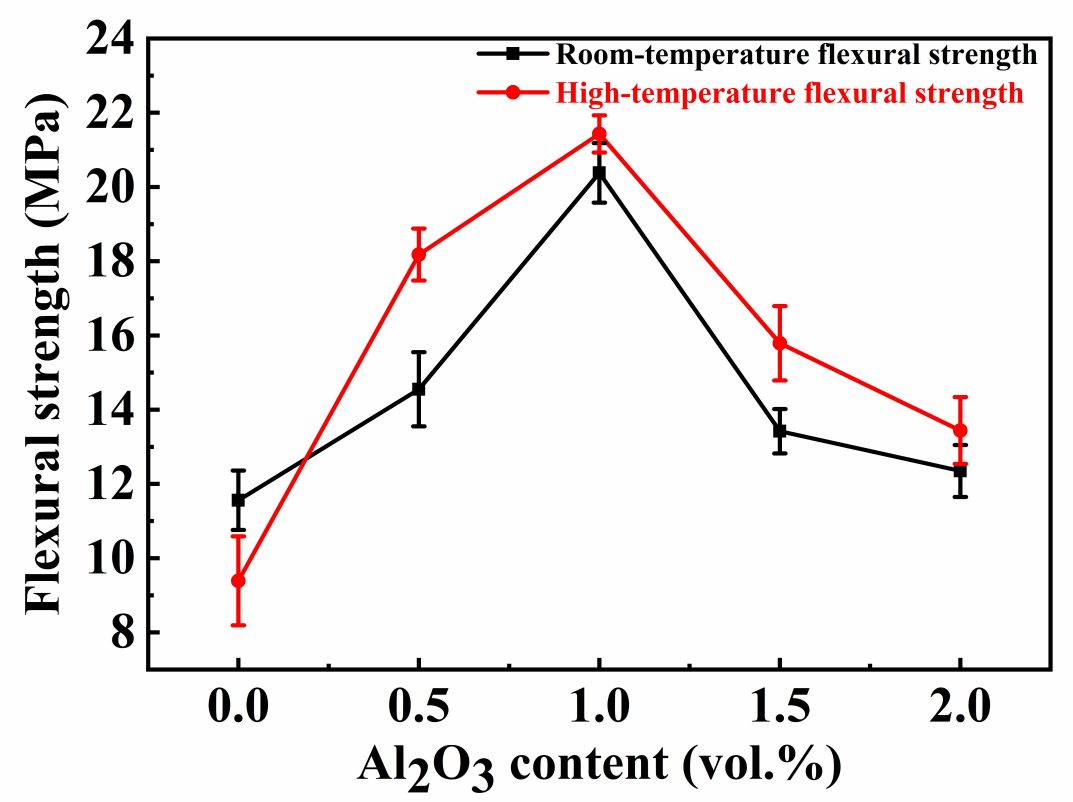

Fig. 6. Flexural strength of silica-based ceramics with different contents of $\mathrm{Al}_{2} \mathrm{O}_{3}$.

\section{Conclusions}

In this study, the silica-based green bodies were fabricated via stereolithography and the 
influence of $\mathrm{Al}_{2} \mathrm{O}_{3}$ content on mechanical properties and microstructures of the as-sintered silica-based ceramics was systematically investigated. With the increase of $\mathrm{Al}_{2} \mathrm{O}_{3}$ content, the linear shrinkage of the sintered ceramics first decreased and then increased, while the room-temperature flexural strength and the high-temperature flexural strength first increased and then decreased. With $\mathrm{Al}_{2} \mathrm{O}_{3}$ added to 1.0 vol.\%, the linear shrinkage reached $1.64 \%$ due to the blocked viscous flow. Nevertheless, the excessive $\mathrm{Al}_{2} \mathrm{O}_{3}$ (1.5 vol.\% and 2.0 vol.\%) could increase the linear shrinkage by promoting the growth of coarse grains which can improve the densification of silica-based ceramics. The $\mathrm{Al}_{2} \mathrm{O}_{3}$ in the silica-based ceramics served as a seed for the crystallization of the fused silica into cristobalite, thereby improving the mechanical properties. Therefore, the room-temperature flexural strength was enhanced to $20.38 \mathrm{MPa}$ and the high-temperature flexural strength was improved to $21.43 \mathrm{MPa}$, as the $\mathrm{Al}_{2} \mathrm{O}_{3}$ content increased to 1.0 vol.\%. However, a large amount of cristobalite generated by the high content of $\mathrm{Al}_{2} \mathrm{O}_{3}$ could easily reduce the internal binding force and cause the propagation of microcracks inside the silica-based ceramics, thus degrading the the room-temperature flexural strength and the high-temperature flexural strength. All in all, the results suggest that using the optimal content of $\mathrm{Al}_{2} \mathrm{O}_{3}$ provides optimum mechanical properties, which are appropriate for the wide application of silica-based ceramic cores and contribute to the manufacturing of hollow blades.

\section{Acknowledgement}

The research work presented in this papaer is supported by National Science and Technology Major Project (2017-VII-0008-0102), National Natural Science Foundation of China (51975230) and Opening Project of State Key Laboratory of High Performance Ceramics and Superfine Microstructure (SKL201903SIC). Meanwhile, the authors are grateful for the State Key Laboratory of Materials Processing and Die \& Mould Technology for mechanical property tests, as well as the Analysis and Testing Center of Huazhong University of Science and Technology for XRD and SEM tests.

\section{References}

[1] Zhong JW, Xu QY. High-Temperature Mechanical Behaviors of $\mathrm{SiO}_{2}$-Based Ceramic Core for Directional Solidification of Turbine Blades. Materials 2020, 13: 4579.

[2] Bae CJ, Kim D, Halloran JW. Mechanical and kinetic studies on the refractory fused silica of 
integrally cored ceramic mold fabricated by additive manufacturing. Journal of the European Ceramic Society 2019, 39: 618-623.

[3] Huseby IC, Borom MP, Greskovich CD. High temperature characterization of silica-base cores for superalloys. American Ceramic Society Bulletin 1979, 58: 448-452.

[4] Kim YH, Yeo J, Lee JS, et al. Influence of silicon carbide as a mineralizer on mechanical and thermal properties of silica ceramic cores. Ceramics International 2016, 42: 14738-14742.

[5] Kim YH, Yeo J, Choi SC. Shrinkage and flexural strength improvement of silica-based composites for ceramic cores by colloidal alumina infiltration. Ceramics International 2016 42: 8878-8883.

[6] Chen X, Zheng WL, Zhang J, et al. Enhanced thermal properties of silica ceramic cores prepared by coating alumina/mullite on the surface of fused silica powders. Ceramics International 2020, 46: 11819-11827.

[7] Kazemi A, Faghihi-Sani MA, Alizadeh HR. Investigation on cristobalite crystallization in silica ceramic cores for investment casting. Journal of the European Ceramic Society 2013, 33: 3397-3402.

[8] Chen ZW, Li ZY, Li JJ, et al. 3D printing of ceramics: A review. Journal of the European Ceramic Society 2019, 39: 661-687.

[9] Chen Z, Sun XH, Shang YP, et al. Dense ceramics with complex shape fabricated by 3D printing: A review. Journal of Advanced Ceramics 2021, 10: 195-218.

[10] Li H, Liu YS, Liu YS, et al. Effect of sintering temperature in argon atmosphere on microstructure and properties of 3D printed alumina ceramic cores. Journal of Advanced Ceramics 2020, 9: 220-231.

[11] Liu SS, $\mathrm{Li} \mathrm{M}, \mathrm{Wu}$ JM, et al. Preparation of high-porosity $\mathrm{Al}_{2} \mathrm{O}_{3}$ ceramic foams via selective laser sintering of $\mathrm{Al}_{2} \mathrm{O}_{3}$ poly-hollow microspheres. Ceramics International 2020, 46: 4240-4247.

[12] Yao YX, Qin W, Xing BH, et al. High performance hydroxyapatite ceramics and a triply periodic minimum surface structure fabricated by digital light processing 3D printing. Journal of Advanced Ceramics 2021, 10: 39-48.

[13] Feng CW, Zhang KQ, He RJ, et al. Additive manufacturing of hydroxyapatite bioceramic scaffolds: Dispersion, digital light processing, sintering, mechanical properties, and biocompatibility. Journal of Advanced Ceramics 2020, 9: 360-373. 
[14] Ding GJ, He RJ, Zhang KQ, et al. Stereolithography 3D printing of SiC ceramic with potential for lightweight optical mirror. Ceramics International 2020, 46: 18785-18790.

[15] Grigoryan B, Sazer DW, Avila A, et al. Development, characterization, and applications of multi-material stereolithography bioprinting. Scientific Reports 2021, 11: 1-13.

[16] Chen F, Zhu H, Wu JM, et al. Preparation and biological evaluation of $\mathrm{ZrO}_{2}$ all-ceramic teeth by DLP technology. Ceramics International 2020, 46: 11268-11274.

[17] Kozlov DA, Tikhonova SA, Evdokimov PV, et al. Stereolithography 3D Printing from Suspensions Containing Titanium Dioxide. Russian Journal of Inorganic Chemistry 2020, 65: 1958-1964.

[18] Li H, Hu KH, Liu YS, et al. Improved mechanical properties of silica ceramic cores prepared by 3D printing and sintering processes. Scripta Materialia 2021, 194: 113665.

[19] Kotz F, Arnold K, Bauer W, et al. Three-dimensional printing of transparent fused silica glass. Nature: International weekly journal of science 2017, 544: 337-339.

[20] Cai P, Guo L, Wang H, et al. Effects of slurry mixing methods and solid loading on 3D printed silica glass parts based on DLP stereolithography. Ceramics International 2020, 46: $16833-16841$.

[21] Liu C, Qian B, Liu X, et al. Additive manufacturing of silica glass using laser stereolithography with a top-down approach and fast debinding. RSC Advances 2018, 8: 16344-16348.

[22] Ji SH, Kim DS, Park MS, et al. Sintering Process Optimization for 3YSZ Ceramic 3D-Printed Objects Manufactured by Stereolithography. Nanomaterials 2021, 11: 192.

[23] Mukhtarkhanov M, Perveen A, Talamona D. Application of Stereolithography Based 3D Printing Technology in Investment Casting. Micromachines 2020, 11: 946.

[24] Manière C, Kerbart G, Harnois C. Modeling sintering anisotropy in ceramic stereolithography of silica. Acta Materialia 2020, 182: 163-171.

[25] Liu J, Wang QH, Li YW, et al. Inhibiting crystallization of fused silica ceramic at high temperature with addition of $\alpha-\mathrm{Si}_{3} \mathrm{~N}_{4}$. Ceramics International 2021, 47: 11394-11404.

[26] Wang YY, Li L, Wang ZY, et al. Fabrication of Dense Silica Ceramics through a Stereo Lithography-Based Additive Manufacturing. Solid State Phenomena 2018, 281: 456-462.

[27] Niu SX, Xu XQ, Li X, et al. Enhanced properties of silica ceramic cores by controlled 
particle sizes of cristobalite seeds. Advances in Applied Ceramics 2019, 118: 403-408.

[28] Wang JC. A novel fabrication method of high strength alumina ceramic parts based on solvent-based slurry stereolithography and sintering. International Journal of Precision Engineering and Manufacturing 2013, 14: 485-491.

[29] An GS, Choi SW, Kim Y-H, et al. Effective infiltration with polyethyleneimine-grafted colloidal alumina particles for silica ceramic cores. Journal of the Ceramic Society of Japan 2017, 125: 95-99.

[30] Goswami A, Ankit K, Balashanmugam N, et al. Optimization of rheological properties of photopolymerizable alumina suspensions for ceramic microstereolithography. Ceramics International 2014, 40: 3655-3665.

[31] Zhang S, Sha N, Zhao Z. Surface modification of $\alpha-\mathrm{Al}_{2} \mathrm{O}_{3}$ with dicarboxylic acids for the preparation of UV-curable ceramic suspensions. Journal of the European Ceramic Society 2017, 37: $1607-1616$.

[32] Chen X, Liu CY, Zheng WL, et al. High strength silica-based ceramics material for investment casting applications: Effects of adding nanosized alumina coatings. Ceramics International 2020, 46: 196-203.

[33] Kazemi A, Faghihi-Sani MA, Alizadeh HR. Investigation on cristobalite crystallization in silica ceramic cores for investment casting. Journal of the European Ceramic Society 2013, 33: 3397-3402.

[34] Huang LP, Duffrène L, Kieffer J. Structural transitions in silica glass: thermo-mechanical anomalies and polyamorphism. Journal of Non-Crystalline Solids 2004, 349: 1-9.

[35] Sacks MD, Bozkurt N, Scheiffele GW. Fabrication of mullite and mullite-matrix composites by transient viscous sintering of composite powders. Journal of the American Ceramic Society 1991, 74: 2428-2437.

[36] Duan WJ, Yang ZH, Cai DL, et al. Effect of sintering temperature on microstructure and mechanical properties of boron nitride whisker reinforced fused silica composites. Ceramics International 2020, 46: 5132-5140.

[37] Kazemi A, Faghihi-Sani MA, Nayyeri MJ, et al. Effect of zircon content on chemical and mechanical behavior of silica ceramic cores. Ceramics International 2014, 40: 1093-1098.

[38] Breneman RC, Halloran JW. Effect of Cristobalite on the Strength of Sintered Fused Silica 
Above and Below the Cristobalite Transformation. Journal of the American Ceramic Society 2015, 98: $1611-1617$.

[39] Peacor DR. High-temperature single-crystal study of the cristobalite inversion. Zeitschrift für Kristallographie 1973, 138: 274-298.

[40] Xia GB, He LT, Yang DA. Preparation and characterization of $\mathrm{CaO}-\mathrm{Al}_{2} \mathrm{O}_{3}-\mathrm{SiO}_{2}$ glass/fused silica composites for LTCC application. Journal of Alloys and Compounds 2012, 531: 70-76.

[41] Yang ZG, Zhao ZJ, Yu JB, et al. Preparation of silica ceramic cores by the preceramic pyrolysis technology using silicone resin as precursor and binder. Materials Chemistry and Physics 2019, 223: 676-682.

[42] Bae CJ. Integrally Cored Ceramic Investment Casting Mold Fabricated by Ceramic Stereolithography (Ph.D. Thesis). University of Michigan, Ann Arbor, 2008.

[43] Beeley PR, Smart RF. Investment Casting. The University Press, Cambridge, London, United Kingdom, 1995. 
Figures
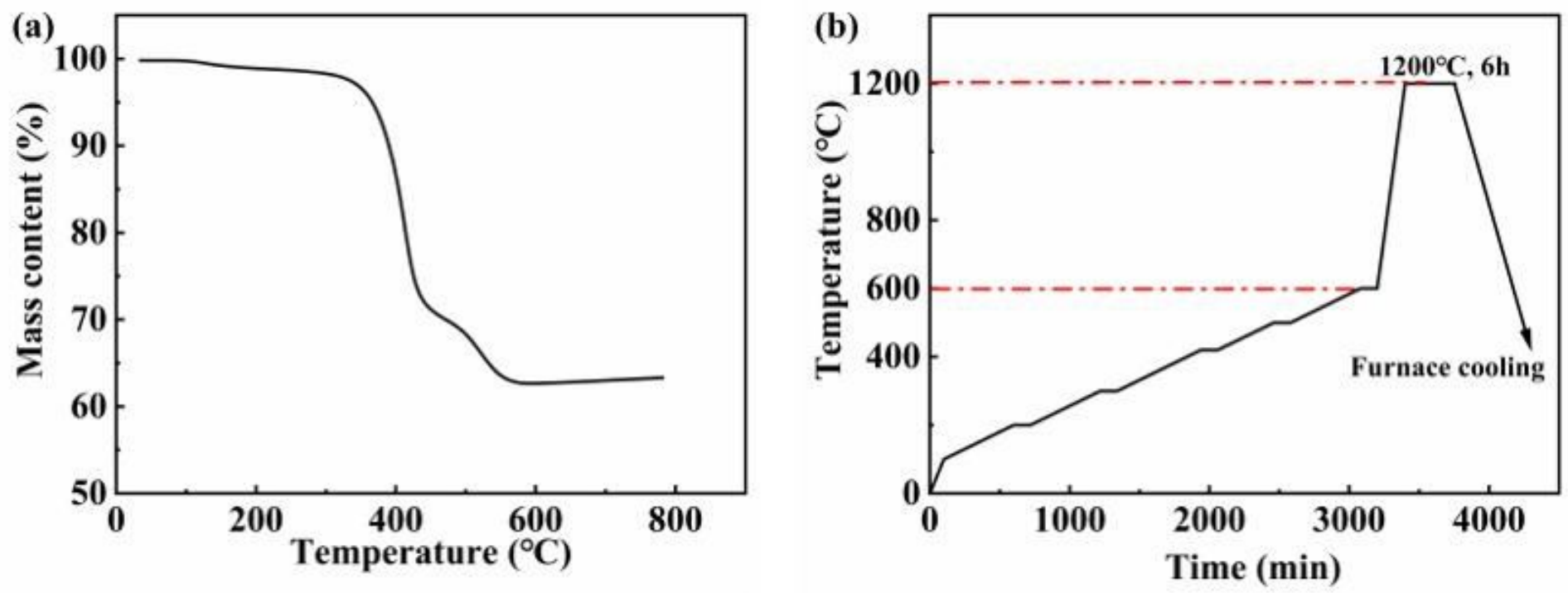

Figure 1

The thermogravimetric curve and thermal treatment of SiO2 green bodies: (a) TGA curve; (b) The debinding and sintering curve. 


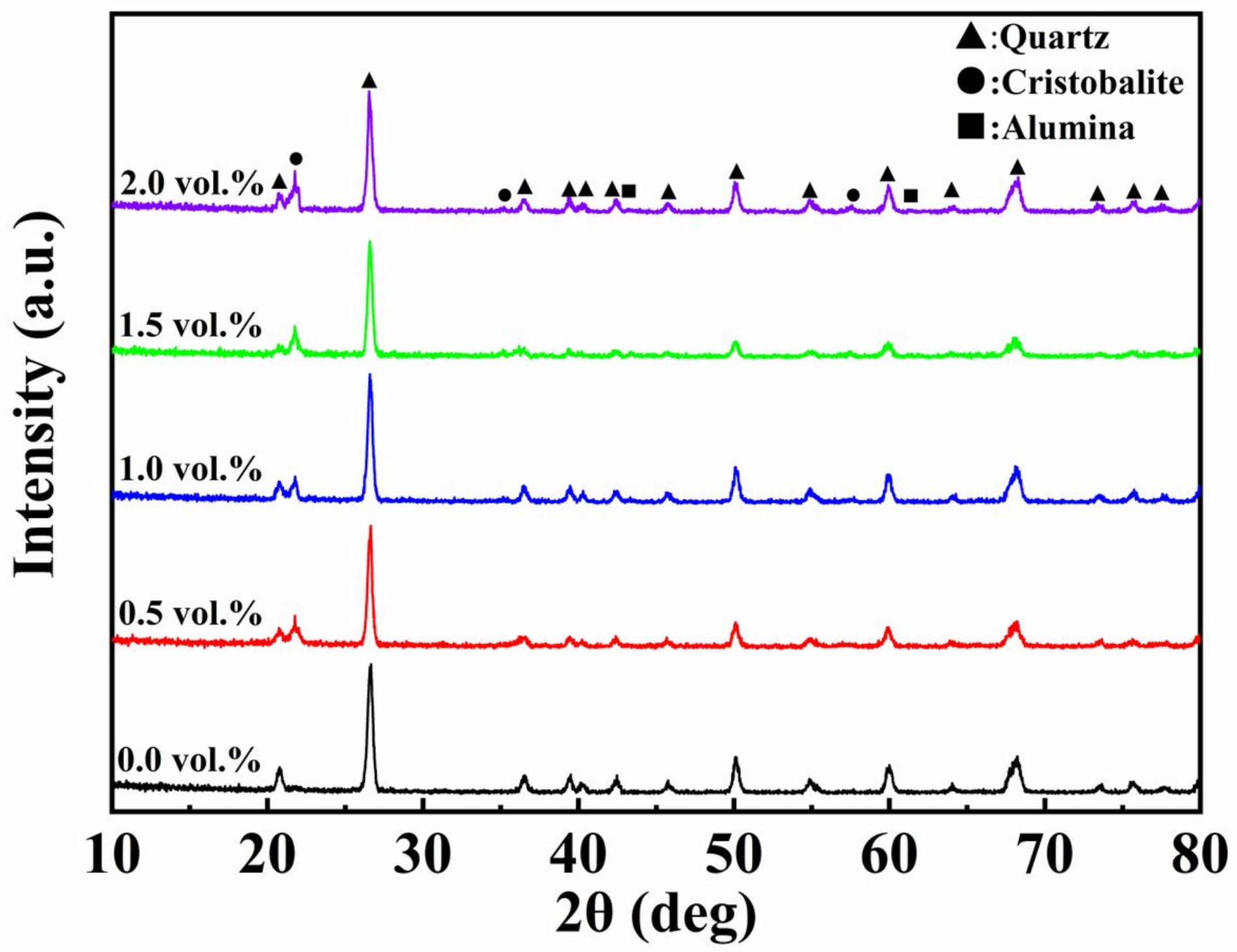

Figure 2

XRD patterns of silica-based ceramic samples with different contents of Al203. 

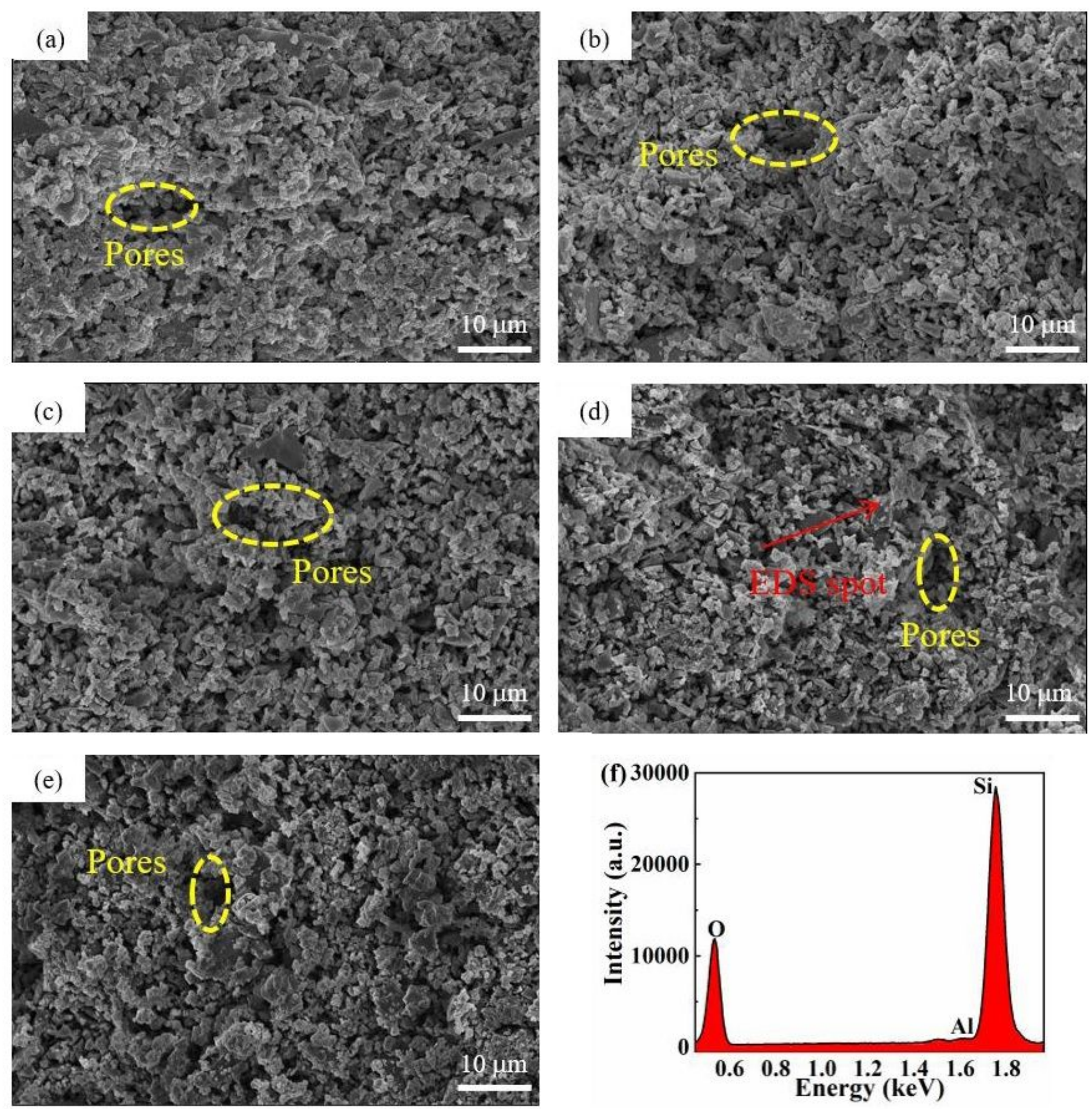

\section{Figure 3}

Microstructures of the silica-based ceramics with various contents of Al203: (a) 0 vol.\%, (b) 0.5 vol.\%, (c) 1.0 vol.\%, (d) 1.5 vol.\%, (e) 2.0 vol.\% and (f) EDS analysis of the EDS spot with 1.5 vol.\% Al2O3. 

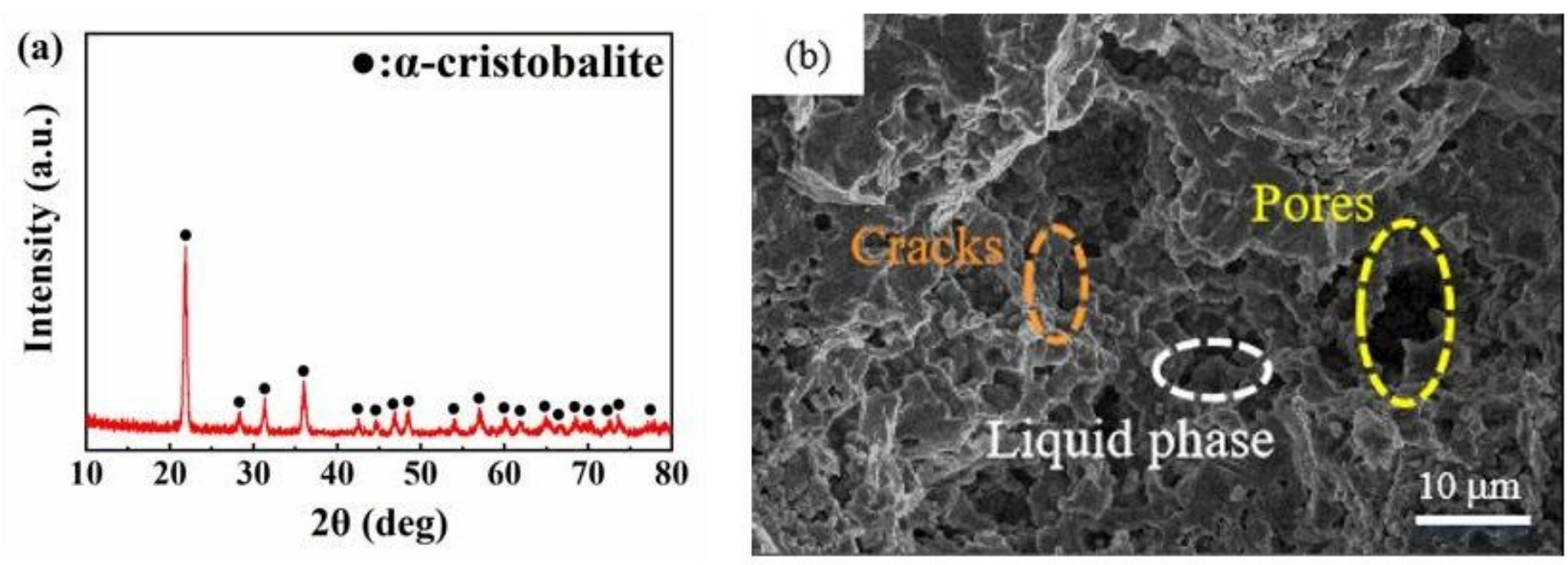

Figure 4

(a) XRD pattern and (b) SEM image of the silica-based ceramics measured at $1550^{\circ} \mathrm{C}$ with $1.0 \mathrm{vol} . \%$ Al203.
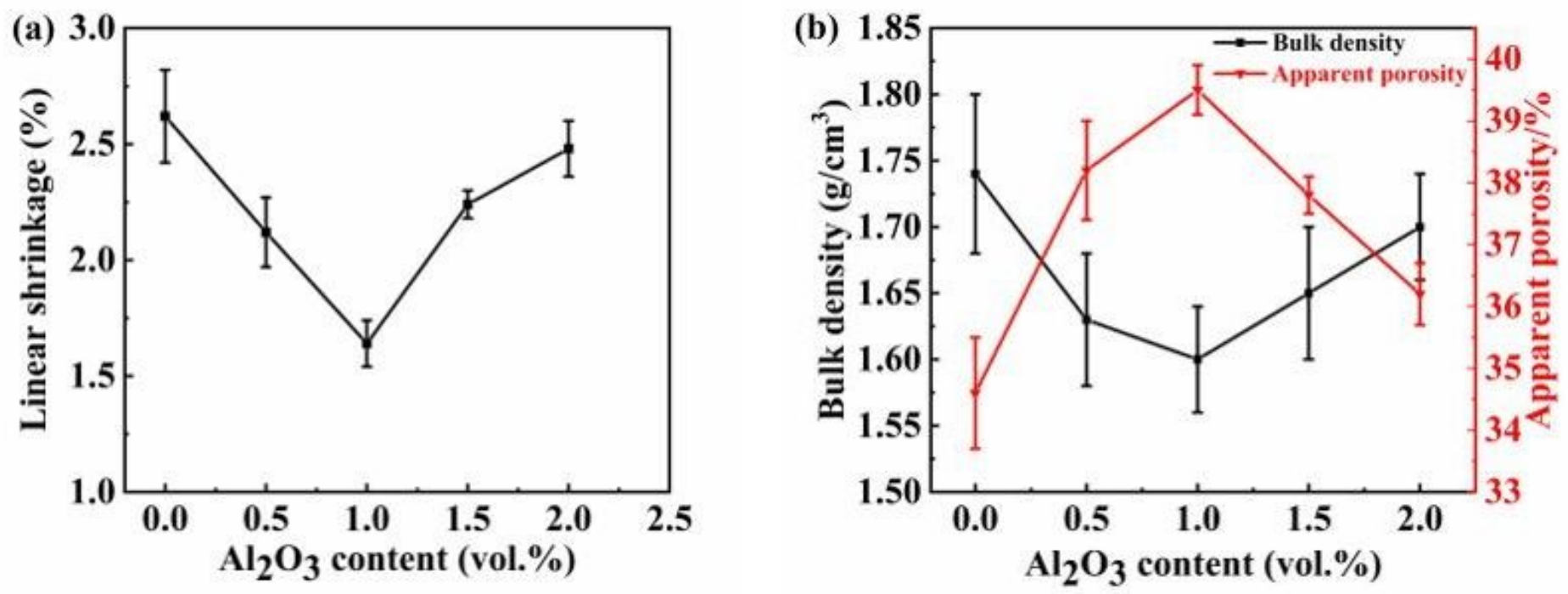

Figure 5

(a) Linear shrinkage and (b) bulk density, apparent porosity of silica-based ceramics with different contents of Al2O3. 


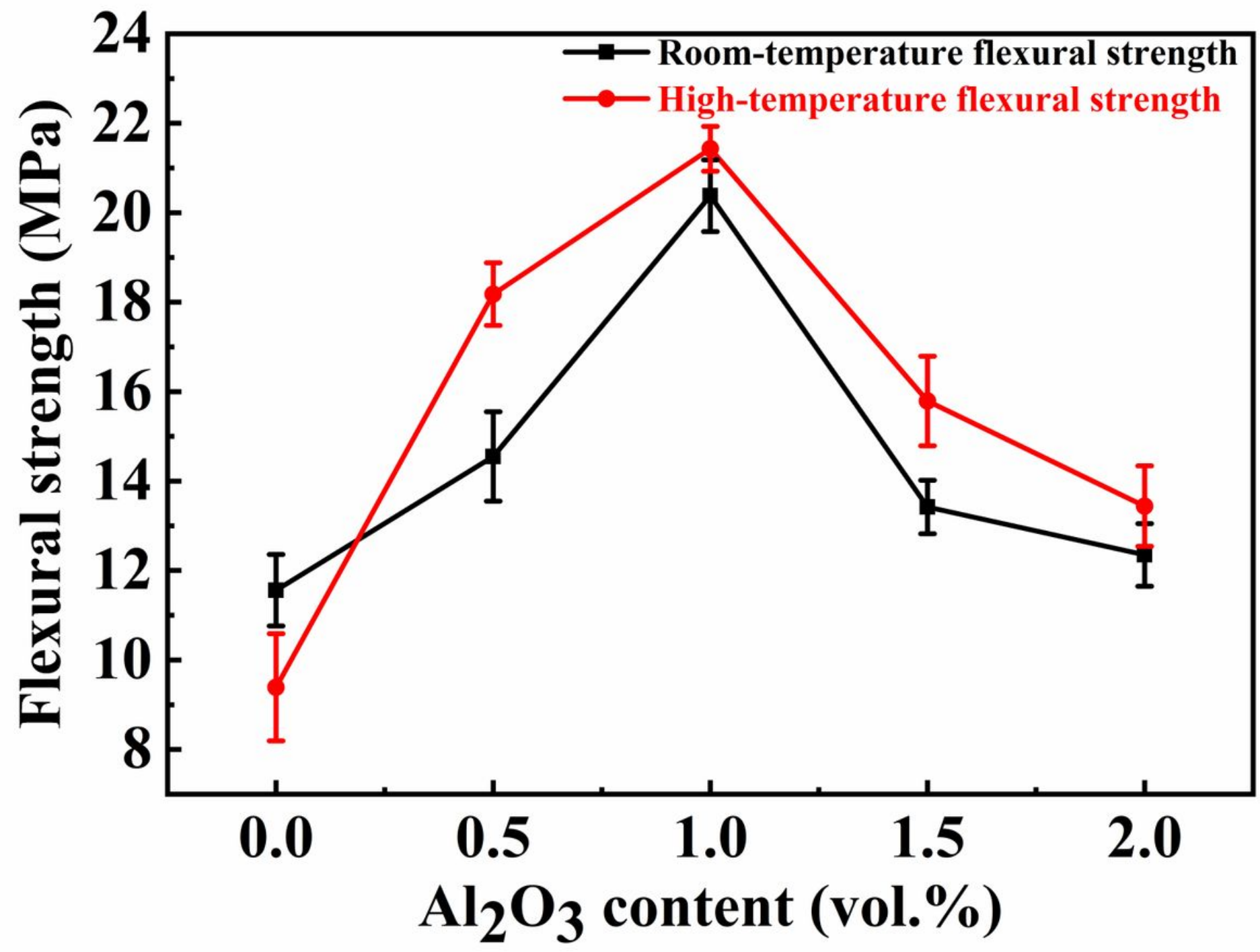

Figure 6

Flexural strength of silica-based ceramics with different contents of Al203. 